\title{
Physicians and advocacy
}

"We are presently in the situation where [we] are meeting with [senior government officials] to garner support for [Providence Health Care's expansion project] and we can now anticipate an irritated reception from them due to bad press attributed to PHC. It is absolutely essential that we get a green light on the ... Project, and this is clearly not the way to achieve it." "...Breach of [our media policy] is unacceptable and may be a disciplinary matter...." (Email to senior staff from Dr. Jeremy Etherington, Vice President Medical Affairs, Providence Health Care, Apr.12, 2005)

I $\mathrm{f}$ it is true that public funding for health care in British Columbia is awarded not on the basis of need but on the condition of getting good press, perhaps Dr. Etherington was right to reprimand Dr. Karen Wanger for speaking to reporters about a critical backlog of patients in her hospital. Perhaps so, given that the Finance Minister Colin Hansen was reported to dismiss Wanger's judgement of the situation at St. Paul's Hospital in Vancouver as mere "guesses." If this is the degree of credibility that a 14-year veteran of one of the country's biggest emergency departments enjoys in the government's eyes - well, we can only wish the hospital's administrators luck in making a better impression.

This ticklish episode has led us to wonder about the responsibility, and the credibility, of physicians as patient advocates. What does it say for the credibility of physicians to know that their institutions may expect them to adhere to policies that preclude giving interviews to "any member of the media unless the interview has been cleared through the Communications Department," or that prohibits any documentary reporting that "runs counter to the mission, vision and values of the organization"? ${ }^{2}$ We would welcome any clarification about the spirit and the aims of this policy.

We can only assume that both Etherington's concern about media sensitivity within the Ministry of Health Services and the potential to adversely affect the Providence Health Care Legacy Project, and Wanger's reporting of the plight of patients in her emergency department arose from a desire to improve patient care. But, since the situation that Wanger reported is not unique to her hospital, and because health care providers in a range of settings are faced with situations that challenge their ethical responsibility to warn patients and the public about serious problems, we need to examine that responsibility more closely, setting specific cases aside.

Do physicians have a duty to pass warnings, criticism or bad news of any kind through the filters of their institutions' media relations offices? As self-governing professionals, is it right for physicians to be so required? These filters can have legitimate purposes, such as ensuring clarity and accuracy. But at what point does nuancing a message slide into sanitizing the truth? Whose call is it to decide?
Our belief is that, in matters affecting public health care institutions, letting it all hang out best serves public trust, patient safety and the forces of positive change. Recently, we saw certain truths about the incidence of Clostridium difficile infection in Canadian hospitals being stifled by media departments and official spokesperson policies; more insidiously, we saw individual physicians gag themselves in anticipation of the disapproval of colleagues or superiors. Had the whistle been blown sooner and louder, fewer patients would have entered hospitals for elective surgeries unaware that they could be facing an unusually high risk of $C$. difficile infection. ${ }^{3,4}$

Physicians, nurses and other health care professionals, when faced with such choices between candour and silence, must weigh their responsibilities to their institutions against their Hippocratic duties to patients and the public at large. There are, no doubt, better and worse ways to deliver bad news. But any health care institution that is disinclined to tolerate unpopular opinions, whistle-blowing or conscientious dissent would do well to examine the risks of this intolerance - risks that include a loss of credibility and public trust, the risk of stalling positive change and the risk of becoming trapped in political games.

Although the public's trust in physicians is centred on professional competence and expertise at the level of the individual patient, this trust extends beyond the patient to research, education and the delivery of health care. The public expects physicians to advocate for their individual and collective well-being. As William Sullivan writes, "It is the function of medicine as a profession to safeguard and promote this trust in the society at large." ${ }_{5}$ The CMA Code of Ethics includes "advocating on behalf of the profession or the public" among the "fundamental responsibilities" of physicians. ${ }^{6}$ Even so, the advocacy role of physicians receives only passing reference in the Code. It is a role that bears further examination, for it is bound to become more important, and more contentious. - CMAF

\section{References}

1. Canadian Broadcasting Corporation. Doctor could face discipline for complaining to media. Available: http://vancouver.cbc.ca/regional/servlet /View?filename=bc_st-pauls-email20050413 (accessed 2005 Apr 28).

2. Providence Health Care. Providence Health Care policy for media relations hospital spokesperson. Internal document no. SH/MEDIA/PHC-Media Policy. Updated 2000 Jan 18.

3. Eggertson L, Sibbald B. Hospitals battling outbreaks of C. difficile. CMAf 2004;171(1):19-21.

4. First, the bad news... [editorial]. CMA7 2004;171(1):5.

5. Sullivan WM. Medicine under threat: professionalism and professional identity. CMA7 2000;162(5):673-5.

6. Canadian Medical Association. CMA code of ethics [policy]. CMAJ 2005;172(8):1053-5. 